\title{
Non-Destructive X-Ray Fluorescence (XRF) Core-Imaging Scanner, TATSCAN-F2
}

\section{Introduction}

During the Deep Sea Drilling Project (DSDP) and the Ocean Drilling Program (ODP), continuous non-destructive measurements such as magnetic susceptibility, gamma-ray density, and P-wave velocity of whole-round and split cores were of great importance for paleoceanographic, structural, and sedimentological studies. The data sets have been used to determine coring strategy, inter-hole correlation, and core-logging integration, and to record the physical condition of the core before discrete sampling. These data series also allow spectral analyses and correlations to orbitally calibrated timescales. Non-destructive measurements hold great potential in the multi-platform Integrated Ocean Drilling Program (IODP) and its associated laboratories at the IODP core repositories.

The recent global warming enigma requires Earth scientists to predict future environmental conditions of the warming Earth and evaluate the effects of these climatic changes; however, capturing records of past climate and global change from deep-sea or lake cores at a resolution of decadal to centennial timescales requires non-destructive measurements on a millimeter or micrometer scale. "TATSCAN" is a code name for recently developed instruments for non-destructive sediment scanning and imaging on such a scale. Two types of non-destructive x-ray fluorescence (XRF) scanners, TATSCAN-F1 and TATSCAN-F2, have been constructed. They provide two-dimensional elemental imaging of the surface of soft sediment and hardrock cores. This article describes the system and the capabilities of the TATSCAN-F2 that has been installed on the Japanese drilling vessel Chikyu and in the IODP Kochi Core Repository (KCR).

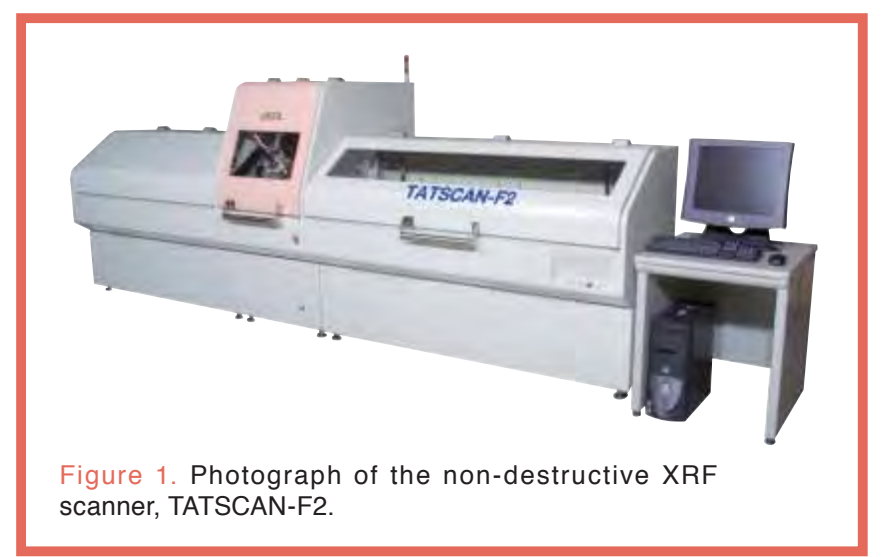

\section{Instrument Specifications}

The TATSCAN-F2 is designed to allow rapid elemental imaging and scanning through energy-dispersive-type XRF (EDXRF) spectroscopy (Fig. 1). It can measure the elemental fluorescence intensity of the surface of split cores, thin sections, or polished hand specimens, up to $150 \mathrm{~cm}$ long and $15 \mathrm{~cm}$ wide, and it employs a new x-ray generator with a rhodium ( $\mathrm{Rh}$ ) target that can generate x-rays with a fivetimes higher intensity compared to standard EDXRF instruments used up to now, thus reducing the time needed for individual measurements. The time for a single measurement can be set to 100 seconds and still yield enough data to quantify elements within a 1-cm-long core increment, resulting in a scanning time of 250 minutes for a standard length core section. The sample chamber is filled with air, so it can be used for processing wet, dry, or powdered samples. The measurement device is automatically laser guided to a 1-mm distance between the measurement spot and the sample surface. To minimize x-ray absorption by the vapor in the surrounding air, a He-filled apparatus is installed around the measurement window, including the x-ray generator and the detector. This allows for quantifying of light elements well enough to detect subtle sedimentary cycles or episodic event layers.

The TATSCAN-F2 can measure in diameters of $0.8 \mathrm{~mm}$ or $7 \mathrm{~mm}$, and with the generator and the detector positioned at a $45^{\circ}$ angle to the sample surface, the incident field of x-rays on the sample surface has an ellipsoidal shape, yielding practical measurement diameters of $1.13 \mathrm{~mm}$ and $9.9 \mathrm{~mm}$, respectively. The scanning resolution is flexible and controlled by the operating software, with minimum scanning resolution of approximately $1 \mathrm{~mm}$. Possible options include spot measurements, line scanning and two-dimensional map imaging. Table 1 lists the quantitative accuracy of the TATSCAN-F2, achieved with discrete tablets of pressedpowder standard samples.

The TATSCAN-F1 is designed to achieve very highresolution measurements of two-dimensional elemental distributions. It uses measurement diameters of 40, 100, 400, and $1900 \mu \mathrm{m}$ and a scanning resolution of $10 \mu \mathrm{m}$. It therefore provides the same level of analytical precision as normal EDXDF. As the scan of a whole section in high resolution requires significant time, the core is first scanned with the faster TATSCAN-F2. The results of this initial scan help to 
Table 1. Analytical accuracy* of the major elements of the TATSCAN-F2.

\begin{tabular}{|c|c|c|}
\hline & Range of contents & $\begin{array}{l}\text { Measurement } \\
\text { diameter } 7 \mathrm{~mm}\end{array}$ \\
\hline $\mathrm{Na}_{2} \mathrm{O}$ & $2.52-4.75$ wt $\%$ & $0.48 \%$ \\
\hline $\mathrm{MgO}$ & $0.05-35.01 w t \%$ & $0.24 \%$ \\
\hline $\mathrm{Al}_{2} \mathrm{O}_{3}$ & $5.56-18.94 \mathrm{wt} \%$ & $0.14 \%$ \\
\hline $\mathrm{SiO}_{2}$ & $0.21-98.46 \mathrm{wt} \%$ & $0.23 \%$ \\
\hline $\mathrm{P}_{2} \mathrm{O}_{5}$ & $0.02-0.70 w t \%$ & $0.05 \%$ \\
\hline S & $0.00-1.35$ wt $\%$ & $0.01 \%$ \\
\hline $\mathrm{K}_{2} \mathrm{O}$ & $0.00-4.34$ wt $\%$ & $0.04 \%$ \\
\hline $\mathrm{CaO}$ & $0.05-98.55$ wt $\%$ & $0.29 \%$ \\
\hline $\mathrm{TiO}_{2}$ & $0.00-1.61 \mathrm{wt} \%$ & $0.02 \%$ \\
\hline $\mathrm{MnO}$ & $0.00-0.30 w t \%$ & $0.01 \%$ \\
\hline $\mathrm{Fe}_{2} \mathrm{O}_{3}$ & $0.04-18.61 \mathrm{wt} \%$ & $0.22 \%$ \\
\hline
\end{tabular}

* For the accuracy test, repeated measurements of 11 standard samples produced by the Geological Survey of Japan have been used. Range of the contents represents the range of the standard sample for each element. The accuracy (absolute error) for a 7-mm measurement diameter is calculated as the standard deviation of the measurement versus the average of repeated measured values.

target specific intervals for subsequent high-resolution measurements with the TATSCAN-F1. The TATSCAN-F1 is currently installed only in the Institute for Research on Earth Evolution (IFREE) at the Japan Agency for Marine EarthScience and Technology (JAMSTEC).

\section{Critical Conditions for Non-Destructive Measurements}

The quality of the measurements with the non-destructive $\mathrm{XRF}$ scanner depends strongly on the sample condition. The measurements are affected by the x-ray attenuation (i.e., attenuation coefficient of the bulk sample, atmospheric density, and distance between sample surface and detector). Three particularly critical factors for XRF scanning are the distance between the sample surface and the detector, the smoothness and flatness of the sample surface, and the preservation conditions of the water content. In our experience, a difference of $1 \mathrm{~mm}$ from spectroscopic setting point results in $10 \%$ attenuation for the $\mathrm{x}$-ray of $\mathrm{Si}$ in the atmosphere of air; this represents a $2 \%$ measurement error for quantifying Si. Another difficulty arises from the fact that a difference in water content within a core section or among successive cores may yield different results for a specific element. This may happen even if the recovered core is carefully split for XRF scanning, because the x-rays are attenuated by water on the surface of the wet core. It is therefore very important to keep the core material under the same conditions after coring and splitting. To allow better comparison of data, the elemental ratio of the result for wet sediment cores is usually used.

Another significant issue concerns $\mathrm{x}$-ray attenuation by the plastic-wrap cover used to protect the core. Commercial plastic wraps using polyethylene, polypropylene, or polyester cause problems because of high x-ray absorption rates, especially for the light elements. For scans with the TATSCAN-F2 a very thin prolene film that has a high x-ray transmission rate is used to cover the wet core.

\section{Application Examples}

About $13 \mathrm{~m}$ of Cretaceous sedimentary rock cores, including the layers with Ocean Anoxic Event (OAE) Ia (Goguel) from southeastern France, were scanned with the TATSCAN-F2 (Fig. 2). All split cores were carefully split and polished. Organic-rich, dark-colored intervals of the Goguel event were intercalated in the continuous alternating sequence of marlstone and limestone. The major element variations of the cores were obtained by continuous, nondestructive, TATSCAN-F2 measurements using a 1-cm scan diameter and a 5-mm scanning interval. $\mathrm{CaCO}_{3}$ and $\mathrm{Al}_{2} \mathrm{O}_{3}$ contents correspond distinctly to the sedimentary cycle of the marlstone-limestone alternation, represented by a gray image and color reflectance; increasing spikes of total $\mathrm{Fe}_{2} \mathrm{O}_{3}$ at about $9.5 \mathrm{~m}$ core length below the Goguel event and at about $7 \mathrm{~m}$ core length in the lower part of the Goguel correspond distinctly to sporadic pyrite nodules. In this case, the TATSCAN-F2 measurement successfully detected the sedimentary cycles of $\mathrm{CaCO}_{3}$ and episodic events of pyrite accumulation.

Soft, wet sediment core MR99-K03-PC1 from the Chukchi Sea in the Arctic Ocean was scanned by the TATSCAN-F2 (Fig. 3). Samples wrapped in prolene were scanned using a $1-\mathrm{cm}$ scanning diameter and a $5-\mathrm{mm}$ scanning interval. Color-shaded intervals represent relatively bioturbated, reddish-colored, silty clay layers with a high concentration of dropstones and a high $\mathrm{Ca} / \mathrm{Al}$ ratio corresponding to interglacial seasonal change in seaice conditions.

An artificial conglomerate core has been scanned as two-dimensional elemental images (Fig. 4). The core was made by filling a core liner with 


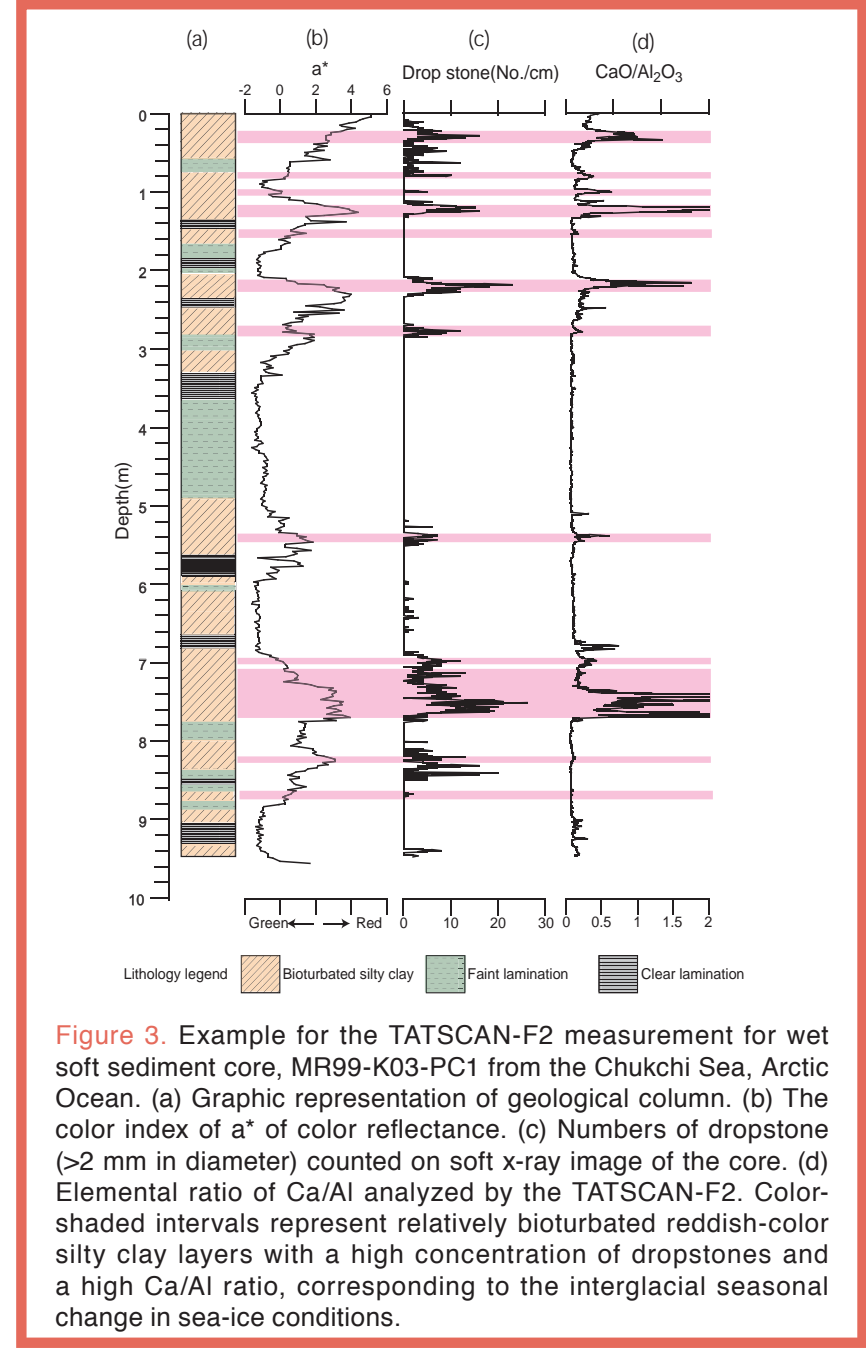

Figure 4. Example of core images using the TATSCAN-F2 with an artificial conglomerate core. The plastic core liner was filled with concrete and gravel-sized rocks and then split. It was scanned with a 7-mm diameter with $1 \mathrm{~cm}$-cube intervals. (a) Split core placed in the TATSCAN-F2. (b) 2-dimensional elemental imaging of major elements analyzed by the TATSCAN-F2. The colors represent concentrations in wt $\%$. The color bar on the left side of each image corresponds to the content image, brighter colors representing a

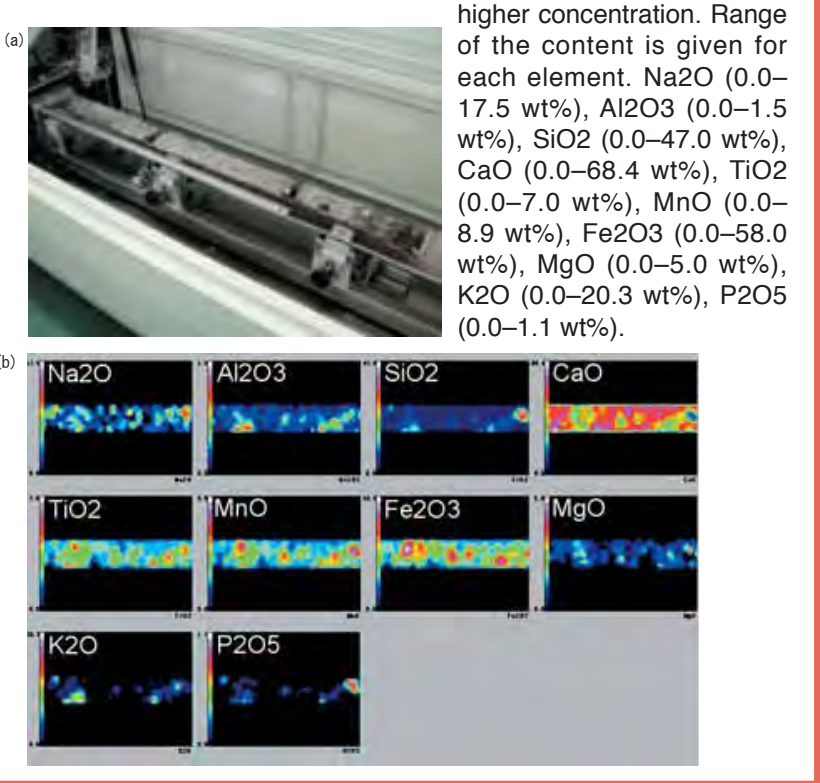

concrete and gravel-sized rocks. Gravel can be easily recognized by the brighter color (high content) in each elemental image of $\mathrm{Al}_{2} \mathrm{O}_{3}, \mathrm{TiO}_{2}, \mathrm{MnO}$, and $\mathrm{Fe}_{2} \mathrm{O}_{3}$ with a $\mathrm{CaCO}_{3}$ matrix.

\section{Advantages and Limitations of Non- Destructive Measurements}

The TATSCAN shows its strengths at rapid and automated measurements with $<1 \%$ quantitative error. It performs very well in detecting sedimentary cycles or events without destroying sedimentary structures and structural features, or where discrete measurements cannot be done quickly or efficiently. The data precision, however, depends strongly on a high standard of sample preparation, in particular concerning a smooth, flat surface and preservation of initial water content. We strongly recommend that users learn the advantages and limitations of non-destructive XRF scanning and the necessarily careful assessment of the data quality and sample conditions before using this technique. It might be necessary to combine discrete measurements with nondestructive scanning measurements to fully evaluate the usefulness of scan-data for scientific research.

For more information about the TATSCAN-F1 or -F2, technical information, or scanning inquiries, please contact Tatsuhiko Sakamoto (tats-ron@jamstec.go.jp).

\section{Authors}

Tatsuhiko Sakamoto, IFREE, JAMSTEC, Natsushima-cho 2-15, Yokosuka 237-0061, Japan, e-mail: tats-ron@jamstec. go.jp

Kazushi Kuroki, CDEX, JAMSTEC, Yokohama Institute for Earth Science, 3173-25 Showa-machi, Kanazawa-ku, Yokohama 236-0001, Japan.

Toshikatsu Sugawara, Department of Marine Science, Marine Works Japan Ltd., c/o Kochi Institute for Core Sample Research, JAMSTEC, B200 Monobe, Nankoku Kochi 783-8502, Japan.

Kan Aoike, CDEX, JAMSTEC, c/o Kochi Institute for Core Sample Research, JAMSTEC, B200 Monobe, Nankoku Kochi 783-8502, Japan.

Koichi Iijima, IFREE, JAMSTEC, Natsushima-cho 2-15, Yokosuka 237-0061, Japan.

Saiko Sugisaki, Department of Polar Science, The Graduate University for Advanced Studies, c/o National Institute of Polar Research, 9-10, Kaga 1-chome, Itabashi-ku, Tokyo 1738515, Japan.

\section{Figure Credits}

Fig 1: Photo provided by Tatsuhiko Sakamoto.

Figs 2 and 4: Data produced by Koichi Iijima and Tatsuhiko Sakamoto.

Fig 3: Data produced by Saiko Sugisaki and Tatsuhiko Sakamoto. 